\title{
Analisis Pengendalian Kualitas Produksi Dengan Metode Six- Sigma Pada Industri Air Minum PT Asera Tirta Posidonia, Kota Palopo
}

\section{Quality Control Analysis of Production with Six-Sigma Method in Drinking Water Industry PT. Asera Tirta Posidonia}

\author{
Didiharyono $^{1 \text { (*) }}$, Marsal ${ }^{2)}$, Bakhtiar ${ }^{3)}$ \\ 1,2,3) Universitas Andi Djemma Palopo
}

Received 20 $0^{\text {th }}$ July $2018 /$ Accepted $20^{\text {th }}$ September 2018

\begin{abstract}
ABSTRAK
Six sigma merupakan salah satu metode yang sedang berkembang di dunia saat ini. Penerapan six sigma diharapkan dapat mengurangi kegagalan (kerusakan) dalam pencapaian sasaran mutu yang diinginkan dalam peningkatan jumlah produksi. Penelitian ini bertujuan untuk mengetahui analisis pengendalian kulitas produksi dengan metode Six Sigma dalam peningkatkan mutu produksi pada industri air minum PT Asera Tirta Posidonia. Jenis penelitian yang digunakan adalah penelitian terapan (applied research) dengan data kuantitatif. Prosedur penelitian yang digunakan pada penelitian ini adalah metode Six Sigma dengan tahapan Define, Measure, Action, Improve dan Control. Hasil penelitian yang dilakukan yaitu pertama, tahap define merupakan mendefinisikan masalah standar kualitas dalam proses produksi perusahaan, mendefinisikan rencana tindakan yang harus dilakukan serta menetapkan sasaran dan tujuan peningkatan kualitas Six Sigma. Kedua, tahap measure. Pada tahapan ini pengukuran karakteristik kualitas produk yang dihasilkan pada proses produksi dilakukan oleh perusahan sehingga peneliti hanya melakukan pengumpulan data atau dokumentasi yang telah dibuat oleh pihak bagian produksi. Ketiga, tahap analyze dihitung mulai dari nilai Central Limit, Upper Control Limit (UCL), Lower Control Limit (LCL) serta perhitungan DPMO dan nilai Sigma. Berdasarkan perhitungan nilai Sigma, rata-rata tingkat sigma 1,929 atau berada pada kondisi 2 sigma dengan kemungkinan kerusakan sebesar 335.287 untuk sejuta kali proses produksi atau sebesar 33,5\% Defect Per Million Opportunities (DPMO). Reject Pabrik dengan persentase dari total kerusakan adalah 57,1\% dan Reject Supplier sebanyak 42,9\%. Keempat, tahap improve yaitu dengan melakukan pelatihan bagi karyawan dan melakukan pengawasan pada karyawan bagian produksi, perawatan dan perbaikan mesin secara berkala dan pemilhan kualitas bahan baku yang akan digunakan dalam proses produksi serta pengelompokan produk cacat berdasarkan jenis kecacatan, melakukan pengamatan setiap minggu, pendataan cacat produksi dilakukan secara detail, pengontrolan produk
\end{abstract}

*Korespondensi:

email:muh.didih@gmail.com 


\title{
Didiharyono (2018)
}

cacat dilakukan dengan baik, skill dan kesadaran operator harus ditingkatkan, supervisor bertanggungjawab terhadap produk cacat masing-masing area. Kelima, tahap control yaitu dengan melakukan pencatatan dan penimbangan produk cacat dari masing-masing jenis kerusakan, melaporkan hasil penimbangan kepada supervisor dan pengawasan terhadap produksi oleh ketua bagian produksi secara terus menerus. Berdasarkan kegiatan pengendalian kualitas tersebut, bisa dikatakan bahwa perusahaan cukup memberikan manfaat dalam upaya mengurangi kegagalan produk akan tetapi masih belum maksimal. Sehingga perlu disarankan yaitu sebaiknya perusahaan meningkatkan kapabilitas Sigma dan meningkatkan proses dengan cara melakukan perbaikan terhadap mesin, bahan baku, metode dan lingkungan serta pembinaan dan pengawasan kerja karyawan.

Kata kunci: Pengendalian Kualitas Statistik dan Six Sigma.

\begin{abstract}
This study aims to analyze the quality control of production with Six Sigma method in improving product quality in drinking water industry PT Asera Tirta Posidonia Palopo City. The type of research used is applied research with quantitative data. The research procedure performed through Six Sigma method steps include Define, Measure, Analysis, Improve and Control. The results obtained are first, the define stage is the definition of quality standard problems in the company's production process, define the action plan that must be done, set the goals and objectives of Six Sigma quality improvement. Second, the measure stage. At this stage the measurement of product quality characteristics produced in the production process is done by the company so that researchers only perform data collection or documentation that has been made by the production department. Third, the stape analytical begins with the calculation of the value of Central Limit, UCL, LCL, determine DPMO value and Sigma value determination with average sigma level 1,929 or condition in 2 sigma with probability of damage equal to 335,287 for million times production process (DPMO) or 33,5\%. Fourth, the improvement stage is to supervise the employees of the production, maintenance and repair of machinery on a regular basis and the selection of quality raw materials that will be used in the production process and the grouping of defects product based on disability type, observe every week, in detail, control of defective product is done well, skill and awareness of operator must be enhance, the supervisor is responsible to defective product of each area. Fifth, the control stage is to perform maintenance and repair machinery on a regular basis and sustainable, supervision of raw materials and production employees for the quality of goods produced better, recording and weighing defective products of each type of damage, report the results of weighing to the supervisor and supervision of production continuously. Based on quality control activities, the company simply provide benefits in an effort to reduce product failure but still not maximal. So it should be suggested that the company should improve the capabilities of Sigma and improve the process by making improvements to machinery, raw materials, methods and environment as well as coaching and supervision of employees.
\end{abstract}

Keywords: Statistical Quality Control and Six Sigma. 


\section{PENDAHULUAN}

Setiap industri memastikan sistem perusahan berjalan dengan baik dan berusaha menjaga agar produk yang dihasilkan mampu memenuhi keinginan dan kepuasan konsumen. Hal ini mendorong perusahaan untuk lebih meningkatkan kualitas produk yang dihasilkan sesuai dengan standar dan spesifikasi yang telah ditentukan. Dewasa ini kebutuhan masyarakat terhadap air minum sangat tinggi. Ini dibuktikan dengan jumlah konsumen air minum yang meningkat secara eksponensial karena jumlah produksi air minum satu tahun mencapai 40 juta perliter. Itulah salah satu penyebab lahinya perusahaan-perusahaan industri yang bergerak di bidang air minum dan menjadikan perkembangan pasar bisnis air minum terus meningkat. Hal ini ditunjukan dengan jumlah perusahaan air minum domestik pada saat ini tercatat mencapai 700 perusahaan yang terdaftar di Badan Pengawas Obat dan Minuman (BPOM).

Hal ini memberikan dampak terhadap persaingan bisnis perusahaan air minum yang semakin tinggi. Oleh karena itu, sudah semestinya para pelaku bisnis di bidang ini lebih memperhatikan pengendalian kualitas produksi untuk lebih bisa bersaing dan menunjang program jangka panjang perusahaan, yaitu mempertahankan pangsa pasar atau bahkan menambah pangsa pasar perusahaan. Kualitas produksi sudah semestinya menjadi prioritas yang paling utama dan penting dilakukan oleh perusahaan agar produk yang dihasilkan sesuai dengan standar yang telah ditetapkan perusahaan maupun standar yang telah ditetapkan oleh badan lokal dan internasional yang mengelola standarisasi mutu (ISO). Untuk mendapatkan kualitas produksi yang dapat bersaing dibutuhkan metode pengendalian kualitas produk yang berkesinambungan. Ada bebarapa konsep metode pengendalian kualitas produksi di antaranya Total Quality Management (TQM), Statistical Process Control (SPC) dan metode Six Sigma.

Pengendalian kualitas statistik dengan metode Six Sigma sering diterapkan oleh perusahaan dalam pengendalian kualitas produk. Pengendalian kualitas produk merupakan suatu sistem pengendalian yang dilakukan dari tahap awal suatu proses sampai produk jadi, bahkan sampai pada pendistribusian produk pada konsumen. Metode Six Sigma dapat juga dipandang sebagai pengendalian proses produksi yang menerapkan konsep DMAIC (Define, Measure, Action, Improve, dan Control) dalam peningkatan kualitas (Gaspersz, 2005). Awal tahun 1980-an, metode Six Sigma mulai diperkenalkan aplikasinya pada perusahaan manufaktur oleh Motorola dan secara bertahap diaplikasikan juga pada sektor bisnis lain seperti perbankan, hotel, rumah sakit, migas, dan sektor lainnya. Tidak hanya Motorola, tetapi masih banyak perusahaan besar seperti General Electric, Texas Instruments, Allied Signal, Eastman Kodak, Borg-Warner Automotive, GenCorp, Navistar International and Siebe PLC juga menerapkan Six Sigma.

Dalam konteks Indonesia, aplikasi Six Sigma relatif baru. Banyak perusahaan di Indonesia mengaplikasikan Six Sigma karena perusahaan induk-nya di Amerika dan Eropa telah mengaplikasikannya seperti General Electric Indonesia, Caltex, dan perusahaan lainnya. Tidak hanya perusahaan barat yang mencoba menggunakan Six Sigma, tetapi juga perusahaan Jepang menggunakannya tanpa meninggalkan aplikasi peningkatan kualitas dasarnya, tidak terkecuali perusahaan PT X yang memproduksi 
product stationary seperti Art Color Pipe File, Clear File, G-Box, Drawing File, Stamp maker, dan lainnya. Langkah kerja DMAIC merupakan langkah kerja yang penting yang perlu dilakukan secara sistematis guna mencapai hasil peningkatan kualitas. Metode Six Sigma untuk meningkatkan kualitas penting dilakukan perusahaan agar peningkatan daya saing produk semakin baik dalam era yang semakin kompetitif dan dinamis ini. Aplikasi tersebut perlu ditunjang oleh adanya metode dan tools yang sistematis dan komprehensif agar pelaksanaan jalannya perbaikan berjalan dengan baik dan memenuhi target yang hendak dicapai.

Six Sigma merupakan sebuah metode yang digunakan untuk memperbaiki suatu proses dengan memfokuskan pada kegiatan untuk memperkecil variasi proses yang terjadi sekaligus mengurangi cacat produksi dengan menggunakan analisis statistik. Secara sederhana six sigma dapat diartikan sebagai suatu proses yang mempunyai kemungkinan (probabilitas) kecacatan sebesar 0,00034\% atau 3,4 unit kecacatan dalam satu juta unit yang diproduksi. Presentase dan jumlah kecacatan dari beberapa sigma dapat dilihat pada Tabel 1 berikut.

Tabel 1. Tingkat Kecacatan pada Sigma

\begin{tabular}{ccc}
\hline Sigma & DPMO & Presentase Kerusakan \\
\hline 1 & 691.462 & $69,15 \%$ \\
2 & 308.538 & $30,85 \%$ \\
3 & 66.807 & $6,68 \%$ \\
4 & 6.210 & $0,62 \%$ \\
5 & 233 & $0,023 \%$ \\
6 & 3,4 & $0,00034 \%$ \\
\hline
\end{tabular}

Sumber: Pande dkk, 2002

Banyak para peneliti yang mengembangkan metode Six Sigma dengan berbagai pendekatan yang dilakukan. Hung dan Sung (2011) mengkaji aplikasi six sigma proses manufaktur pada indukstri makanan untuk mengurangi biaya kualitas (quality cost). Kemudian Fursule dkk (2012) meneliti manfaat dan batasan metode six sigma. Ganguly (2012) mengkaji perbaikan proses penggilingan (rolling mill) dengan pendekatan six sigma. Metode tersebut dikaji oleh Kabir dkk (2013) dengan melihat penerapan metode Six Sigma dalam perbaikan produksi suatu perusahaan. Selanjutnya, Teneja dan Manchandra (2013) serta Thakore (2014) mengakaji pendekatan Six Sigma dalam memperbaiki produktifitas pada industri manufaktur. Oleh karena itu, penulis mencoba meneliti Analisis Pengendalian Kualitas Produksi dengan Metode Six Sigma pada Industri Air Minum, Kota Palopo. Adapun tujuan dari penelitian ini yaitu untuk mengetahui analisis pengendalian kulitas produksi dengan metode Six Sigma dalam peningkatkan mutu produksi pada industri air minum PT Asera Tirta Posidonia. 


\section{METODE PENELITIAN}

Jenis penelitian yang digunakan adalah penelitian terapan (applied research) dengan data kuantitatif. Penelitian terapan merupakan penelitian yang dikerjakan dengan maksud untuk menerapkan, mengkaji dan mengevaluasi kemampuan suatu teori yang diterapkan dalam pemecahan masalah secara praktis di bidang kehidupan sehari-hari. Prosedur penelitian yang digunakan pada penelitian ini adalah metode Six Sigma dengan tahapan DMAIC yaitu:

1. Tahap Define. Pada tahapan ini dilakukan pengumpulan data baik data kuantitatif maupun kualitatif dari perusahaan sehingga diketahui jenis-jenis kerusakan produk yang dihasilkan pada proses produksi di PT. Asera Tirta Posidonia.

2. Tahap Measure. Pada tahap ini dilakukan pengukuran terhadap karakteristik kualitas produk yang dihasilkan pada proses produksi PT. Asera Tirta Posidonia

3. Tahap Analyze. Pada tahap ini melakukakan analisis terhadap data-data hasil produksi PT. Asera Tirta Posidonia dengan menggunakan tools statistical quality control, dan menganalisis tingkat sigma berdasarkan defect per million opportunities (DPMO) perusahaan.

4. Tahap Improve merupakan tahap peningkatan kualitas Six-sigma dengan melakukan pengukuran (lihat dari peluang, kerusakan, proses kapabilitas saat ini), rekomendasi ulasan perbaikan, menganalisa kemudian tindakan perbaikan.

5. Tahap Control merupakan tahap peningkatan dan penjagaan kualitas dengan memastikan level baru kinerja dalam kondisi standar dan terjaga nilai-nilai peningkatannya yang kemudian didokumentasikan dan disebarluaskan yang berguna sebagai langkah perbaikan untuk kinerja proses berikutnya.

\section{HASIL DAN PEMBAHASAN}

Adapun tahapan dalam proses penelitian yaitu Define, Measure, Analyze, Improve, dan Control (DMAIC).

\section{Tahap Define}

Berdasarkan hasil penelitian dan identifikasi yang dilakukan di PT. Asera Tirta Posidonia, produk yang dihasilkan dihasilkan digolongkan yaitu jenis Air Minum Dalam Kemasan (AMDK) dengan ukuran CUP 220 ML dengan nomor SNI 01-3553-2006 LSPr018-IDN dan Nomor BPOM RI 265220002050. Ada dua kerusakan (reject) dalam proses produksi yang terjadi yaitu Reject Supplier dan Reject Pabrik (perdos). Reject Supplier adalah kerusakan yang terjadi saat persediaan bahan baku yaitu kerusakan pada gelas plastik yang berukuran $220 \mathrm{ML}$ saat pemesanan, misalkan gelasnya retak-retak, sobek dan tidak sesuai ukuran. Sedangkan Reject Pabrik adalah kerusakan yang terjadi pada proses produksi dengan menggunakan tenaga mesin, misalkan gelasnya yang bocor dan cetakan logo miring. Adapun hasil produksinya dan produk yang cacat akan ditunjukan pada Tabel 2 berikut: 
Tabel 2. Data Hasil Proses Produksi

\begin{tabular}{cccccc}
\hline No & $\begin{array}{c}\text { Produksi } \\
\text { (perdos) }\end{array}$ & $\begin{array}{c}\text { Reject } \\
\text { Supplier } \\
\text { (perdos) }\end{array}$ & $\begin{array}{c}\text { Reject Pabrik } \\
\text { (perdos) }\end{array}$ & $\begin{array}{c}\text { Jumlah } \\
\text { Reject }\end{array}$ & $\begin{array}{c}\text { Total } \\
\text { Produksi }\end{array}$ \\
\hline 1 & 85010 & 19056 & 31064 & 50120 & 135130 \\
2 & 88103 & 37373 & 28550 & 65923 & 154026 \\
3 & 73936 & 13847 & 26978 & 40825 & 114761 \\
4 & 74100 & 14307 & 25386 & 39693 & 113793 \\
5 & 73331 & 15078 & 32014 & 47092 & 120423 \\
6 & 81320 & 13322 & 27605 & 40927 & 122247 \\
7 & 59136 & 13488 & 18309 & 31797 & 90933 \\
8 & 74762 & 13340 & 13727 & 27067 & 101829 \\
9 & 92265 & 14936 & 20542 & 35478 & 127743 \\
10 & 88611 & 15960 & 20075 & 36035 & 124646 \\
11 & 100380 & 21744 & 21659 & 43403 & 143783 \\
12 & 78984 & 19523 & 15957 & 35480 & 114464 \\
\hline Jumlah & 969938 & 211974 & 281866 & 493840 & 1463778 \\
\hline
\end{tabular}

Berdasarkan Tabel 2 di atas terlihat bahwa total produksi Air Minum Dalam Kemasan 969938 perdos, total Reject Supplier sebanyak 211974 perdos dan total Reject Pabrik sebanyak 281866 perdos, dimana setiap dos berisi 48 gelas dengan ukuran 220 ML.

\section{Tahap Measure}

Pada tahap ini pengukuran karakteristik kualitas produk yang dihasilkan pada proses produksi dilakukan oleh bagian produksi PT. Asera Tirta Posidonia, sehingga peneliti hanya melakukan pengumpulan data atau dokumentasi yang telah dibuat oleh pihak bagian produksi.

\section{Tahap Analyze}

Pada tahap ini data dianalisis dengan menggunakan Tool Statistical Quality Control terhadap data produksi PT. Asera Tirta Posidonia pada bulan September 2017.

a. Analisis data dengan menggunakan peta kendali p. Adapun langkah-langkahnya sebagai berikut:

1) Menghitung garis pusat (central limit) peta kendali $p$ :

$$
\bar{P}=\frac{\sum p_{i}}{\sum n_{i}}=\frac{493840}{1463778}=0,3373
$$

Menghitung proporsi kerusakan setiap kali proses produksi, digunakan persamaan:

$$
P_{i}=\frac{p_{i}}{n_{i}}
$$


Sehingga, diperoleh nilai $\mathrm{P}$ untuk data $1, P_{1}=\frac{50120}{135130}=0.3709, P_{2}=\frac{65923}{154026}=$ 0.427999

Dan seterusnya sampai dengan perhitungan data ke-12, untuk selengkapnya dapat dilihat pada Tabel 3.

2) Menghitung batas kendali terhadap pengawasan yang dilakukan dengan menetapkan nilai UCL (Upper Control Limit / batas kendali atas) dan LCL (Lower Control Limit / batas kendali bawah).

Untuk data 1 ,

$$
\begin{aligned}
& U C L=\bar{P}+3 \sqrt{\frac{\bar{P}(1-\bar{P})}{n_{i}}}=0,3373+3 \sqrt{\frac{0.3373(1-0,3373)}{135130}}=0,3412 \\
& L C L=\bar{P}-3 \sqrt{\frac{\bar{P}(1-\bar{P})}{n_{i}}}=0.3373-3 \sqrt{\frac{0.3373(1-0.3373)}{135130}}=0,3335
\end{aligned}
$$

Dan seterusnya sampai dengan perhitungan data ke-12, untuk selengkapnya dapat dilihat pada Tabel 3 berikut.

Tabel 3. Perhitungan Batas Kendali

\begin{tabular}{cccccc}
\hline No & $\begin{array}{c}\text { Jumlah } \\
\text { Produksi }\end{array}$ & $\begin{array}{c}\text { Jumlah } \\
\text { Cacat }\end{array}$ & Proporsi (P) & UCL & LCL \\
\hline 1 & 135130 & 50120 & 0,37090209 & 0,34123265 & 0,33351535 \\
2 & 154026 & 65923 & 0,42799917 & 0,34098822 & 0,33375978 \\
3 & 114761 & 40825 & 0,35573932 & 0,34156111 & 0,33318689 \\
4 & 113793 & 39693 & 0,34881759 & 0,34157888 & 0,33316912 \\
5 & 120423 & 47092 & 0,39105486 & 0,34146149 & 0,33328651 \\
6 & 122247 & 40927 & 0,3347894 & 0,34143088 & 0,33331712 \\
7 & 90933 & 31797 & 0,34967504 & 0,34207782 & 0,33267018 \\
8 & 101829 & 27067 & 0,26580837 & 0,34181904 & 0,33292896 \\
9 & 127743 & 35478 & 0,2777295 & 0,34134265 & 0,33340535 \\
10 & 124646 & 36035 & 0,28909873 & 0,34139165 & 0,33335635 \\
11 & 143783 & 43403 & 0,30186462 & 0,34111474 & 0,33363326 \\
12 & 114464 & 35480 & 0,30996645 & 0,34156654 & 0,33318146 \\
\hline
\end{tabular}

Dari tabel di atas kemudian dapat dibuatkankan peta kendali $p$ yang dapat dilihat pada gambar berikut. 


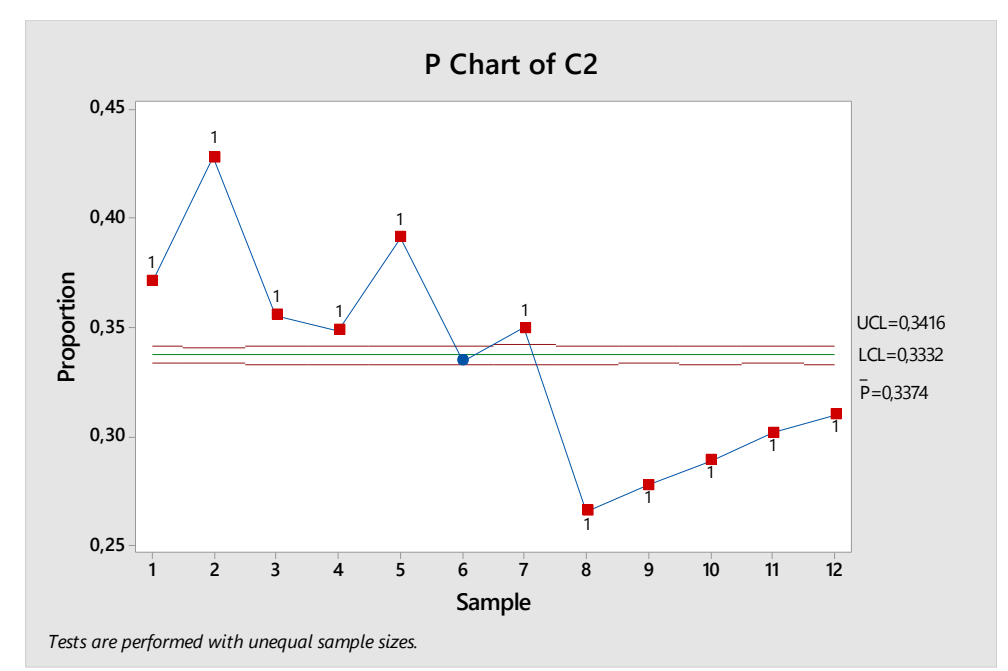

Gambar 1. Peta Kendali $p$ Jumlah Produk Rusak

Pada Gambar 1 tersebut menunjukan bahwa terdapat proporsi kerusakan yang melewati garis batas peta kendali $p$, hal ini menunjukkan bahwa variasi yang dihasilkan pada beberapa kali proses produksi perusahaan berada pada kondisi yang tidak stabil atau out of control (tidak terkendali). Hal ini mengisyaratkan perlunya suatu tindakan perbaikan proses produksi sehingga variasi yang dihasilkan pada beberapa kali proses produksi stabil atau incontrol (terkendali).

b. Menghitung Defect Per-Million Opportunities (DPMO) dan menkonversi nilai sigma berdasarkan tabel sigma. Adapun langkah-langkahnya sebagai berikut :

1) Menghitung DPU (Defect Per Unit) :

Data $1, D P U=\frac{50120}{135130}=0,370902094$

$$
D P U=\frac{\text { Total Cacat Produksi }}{\text { Total Produksi }}
$$

Data 2, DPU $=\frac{65923}{135130}=0,427999169$

Dan seterusnya sampai dengan perhitungan data ke-12, untuk selengkapnya dapat dilihat pada Tabel 4.

2) Menghitung DPMO (Defect Per Million Oportunities)

$$
\text { DPMO }=\frac{\text { Total cacat Produksi }}{\text { Jumlah Produksi }} \times 1.000 .000
$$

Data $1, D P M O=\frac{50120}{135130} \times 1.000 .000=370902,0943$

Data 2, $D P M O=\frac{65923}{135130} \times 1.000 .000=427999,169$

Dan seterusnya sampai dengan perhitungan data ke-12, untuk selengkapnya dapat dilihat pada Tabel 4 berikut. 
Tabel 4. Pengukuran Tingkat Sigma dan Defect Per Million Opportinities (DPMO)

\begin{tabular}{cccccc}
\hline No & $\begin{array}{c}\text { Total } \\
\text { Produksi }\end{array}$ & $\begin{array}{c}\text { Total } \\
\text { Cacat }\end{array}$ & DPU & DPMO & $\begin{array}{l}\text { Nilai } \\
\text { Sigma }\end{array}$ \\
\hline 1 & 135130 & 50120 & 0,370902 & 370902,0943 & 1,829 \\
2 & 154026 & 65923 & 0,427999 & 427999,169 & 1,681 \\
3 & 114761 & 40825 & 0,355739 & 355739,3191 & 1,87 \\
4 & 113793 & 39693 & 0,348818 & 348817,5898 & 1,889 \\
5 & 120423 & 47092 & 0,391055 & 391054,8649 & 1,777 \\
6 & 122247 & 40927 & 0,334789 & 334789,4018 & 1,927 \\
7 & 90933 & 31797 & 0,349675 & 349675,0355 & 1,886 \\
8 & 101829 & 27067 & 0,265808 & 265808,365 & 2,126 \\
9 & 127743 & 35478 & 0,27773 & 277729,5038 & 2,09 \\
10 & 124646 & 36035 & 0,289099 & 289098,7276 & 2,056 \\
11 & 143783 & 43403 & 0,301865 & 301864,6154 & 2,019 \\
12 & 114464 & 35480 & 0,309966 & 309966,4523 & 1,996 \\
\hline Rata-Rata & 121981,5 & 41153,33 & 0,335287 & 335287,0949 & 1,929 \\
\hline
\end{tabular}

Dari Tabel 4 di atas terlihat bahwa bagian produksi PT. Asera Tirta Posidonia pada Tahun 2017 memiliki tingkat sigma 1,929 atau berada pada kondisi 2 sigma dengan kemungkinan kerusakan sebesar 335.287 untuk sejuta kali proses produksi atau sebesar 33,5\% Defect Per Million Opportunities (DPMO). Hal ini tentu menjadi suatu kerugian bagi perusahaan apabila tidak dilakukan perbaikan proses produksi untuk menekan tingkat kerusakan produk yang dihasilkan setiap proses produksi, sehingga dapat meningkatkan level sigma perusahaan.

Adapun rekomendasi batas toleransi kerusakan yang dapat menjadi target atau acuan perusahaan untuk meningkatkan level sigma perusahaan pada kondisi sekarang (level 2 sigma) menjadi level 3 sigma, level 4 sigma atau bahkan 6 sigma yaitu:

a) Rekomendasi 3 Sigma, yaitu maksimal jumlah kerusakan produk yang dihasilkan tiap kali proses produksi adalah 6,681\% dari jumlah produk yang dihasilkan

b) Rekomendasi 4 Sigma, yaitu maksimal jumlah kerusakan produk yang dihasilkan tiap kali proses produksi adalah $0,621 \%$ dari jumlah produk yang dihasilkan.

c) Rekomendasi 5 Sigma, yaitu maksimal jumlah kerusakan produk yang dihasilkan tiap kali proses produksi adalah $0,023 \%$ dari jumlah produk yang dihasilkan.

d) Rekomendasi 6 Sigma, yaitu maksimal jumlah kerusakan produk yang dihasilkan tiap kali proses produksi adalah $0,00034 \%$ dari jumlah produk yang dihasilkan. 
Tabel 5. Rekomendasi Peningkatan Level Sigma

\begin{tabular}{|c|c|c|c|c|c|c|}
\hline \multirow[b]{2}{*}{ No } & \multirow{2}{*}{$\begin{array}{c}\text { Total } \\
\text { Produksi }\end{array}$} & \multirow{2}{*}{$\begin{array}{l}\text { Kondisi } \\
\text { Cacat (2 } \\
\text { Sigma) }\end{array}$} & \multicolumn{4}{|c|}{ Rekomendasi } \\
\hline & & & $\begin{array}{l}\text { 3 Sigma } \\
(6,681 \%)\end{array}$ & $\begin{array}{c}4 \text { Sigma } \\
(0,621)\end{array}$ & $\begin{array}{c}5 \text { Sigma } \\
(0,023 \%)\end{array}$ & $\begin{array}{c}\text { 6 Sigma } \\
(0,00034 \%)\end{array}$ \\
\hline 1 & 135130 & 50120 & 9028,04 & 839,16 & 31,08 & 0,46 \\
\hline 2 & 154026 & 65923 & 10290,48 & 956,5 & 35,43 & 0,52 \\
\hline 3 & 114761 & 40825 & 7667,18 & 712,67 & 26,4 & 0,39 \\
\hline 4 & 113793 & 39693 & 7602,51 & 706,65 & 26,17 & 0,39 \\
\hline 5 & 120423 & 47092 & 8045,46 & 747,83 & 27,7 & 0,41 \\
\hline 6 & 122247 & 40927 & 8167,32 & 759,15 & 28,12 & 0,42 \\
\hline 7 & 90933 & 31797 & 6075,23 & 564,69 & 20,91 & 0,31 \\
\hline 8 & 101829 & 27067 & 6803,19 & 632,36 & 23,42 & 0,35 \\
\hline 9 & 127743 & 35478 & 8534,51 & 793,28 & 29,38 & 0,43 \\
\hline 10 & 124646 & 36035 & 8327,59 & 774,05 & 28,67 & 0,42 \\
\hline 11 & 143783 & 43403 & 9606,14 & 892,89 & 33,07 & 0,49 \\
\hline 12 & 114464 & 35480 & 7647,34 & 710,82 & 26,33 & 0,39 \\
\hline $\begin{array}{c}\text { Jumlah } \\
\text { Total }\end{array}$ & 1463778 & 493840 & 97795,01 & 9090,1 & 336,7 & 4,98 \\
\hline
\end{tabular}

Berikut ditunjukan grafiknya,

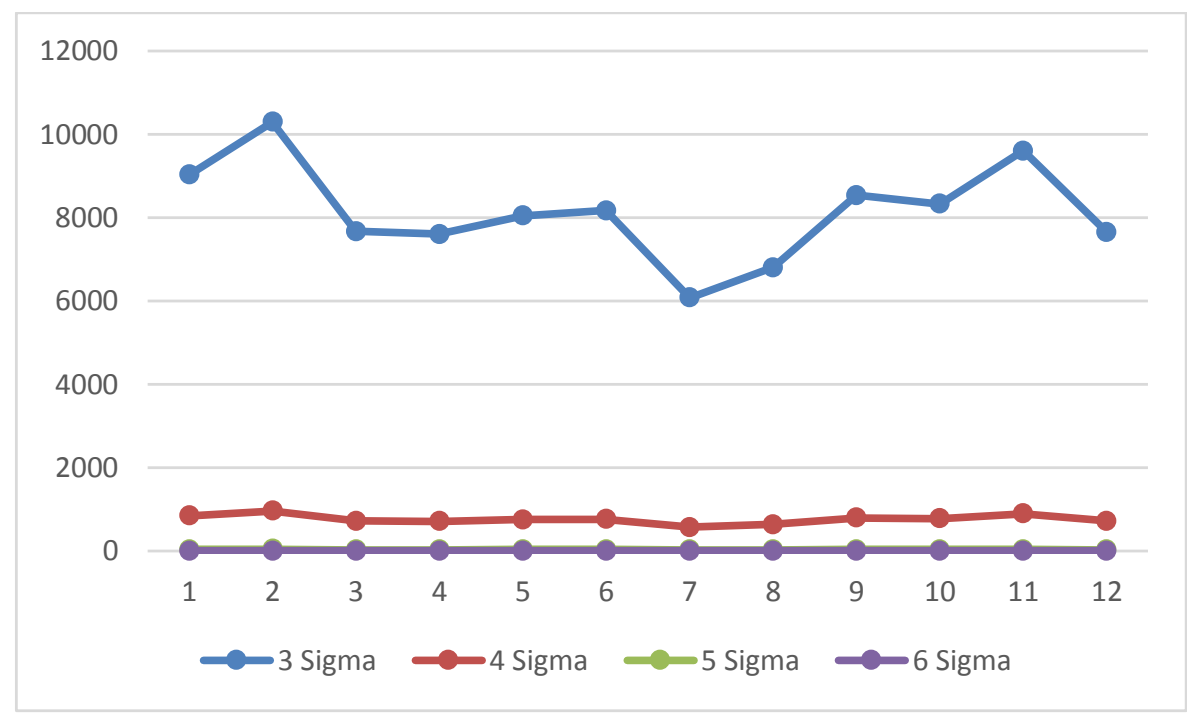

Gambar 2. Rekomendasi Level Sigma

c. Analisis data Jumlah Kerusakan

Menghitung persentase jenis kerusakan produk dengan menggunakan rumus sebagai berikut :

$$
\text { Kerusakan }=\frac{\text { Jumlah kerusakan jenis }}{\text { Jumlah total kerusakan }} \times 100 \%
$$


Adapun jumlah Reject Supplier sebanyak 211974 dos, Reject Pabrik sebanyak 281866 dos dengan jumlah kerusakan keseluruhan sebanyak 493840 dos. Adapun persentase kerusakan yaitu sebagai berikut :

Reject Supplier $=\frac{211974}{493840} \times 100 \%=42,9 \%$

Reject Pabrik $=\frac{281866}{493840} \times 100 \%=57,1 \%$

Perhitungan di atas menunjukan bahwa tindakan terhadap kerusakan yang dihasilkan pada proses produksi dikategorikan menjadi 2 jenis yaitu Reject Supplier dan Reject Pabrik. Tindakan terhadap kerusakan produk paling besar yaitu Reject Pabrik dengan persentase dari total kerusakan adalah 57,1\% dan Reject Supplier sebanyak 42,9\%. Jadi perbaikan dapat dilakukan dengan memfokuskan pada tindakan terhadap kerusakan terbesar yaitu Reject Pabrik yang tejadi pada hasil proses produksi selanjutnya memperbaiki Reject Supplier.

d. Diagram Sebab Akibat (Fish Bone)

Berdasarkan identifikasi yang dilakukan, faktor-faktor yang mempengaruhi dan menjadi penyebab kerusakan produk secara umum yaitu pekerja atau karyawan (people), bahan baku (material), mesin (machine), metode (method) dan lingkungan (environment).

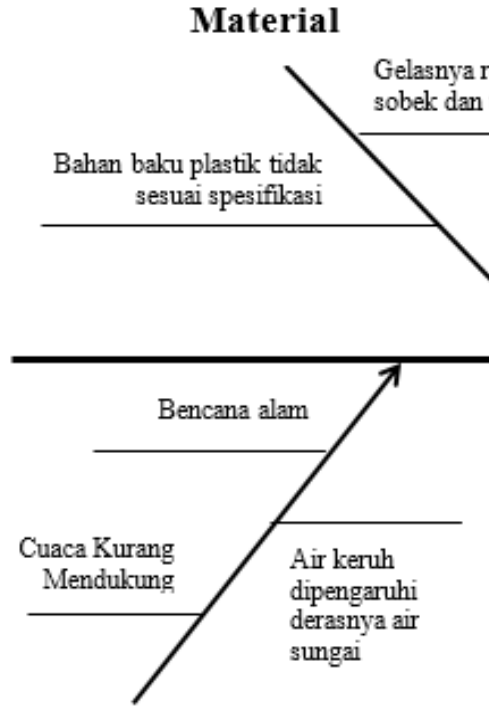

Lingkungan elasnya retak-retak, bek dan tidak sesuai

Tempat penampungan kurang besar
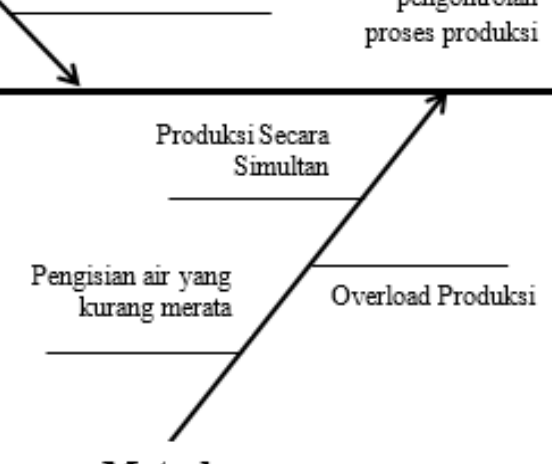

Metode
Pekerja

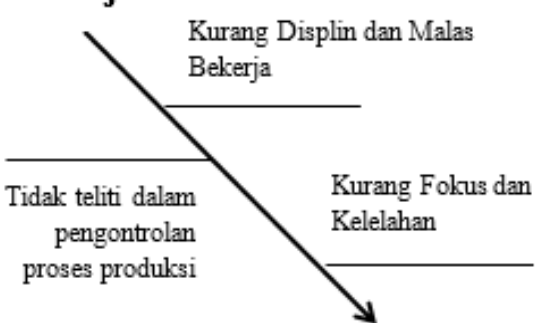

Kurang Displin dan Malas

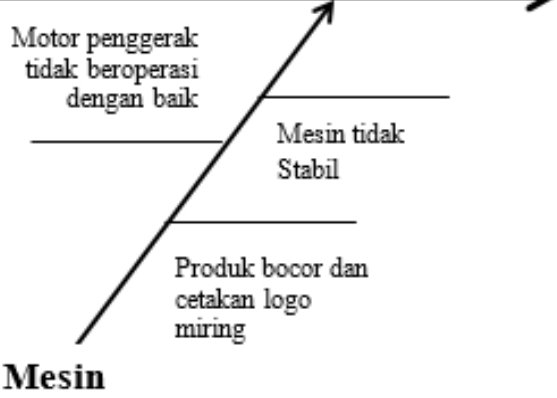

Gambar 3. Diagrgam Sebab Akibat (Fish Bone)

\section{Tahap Improve}

Tahap improve merupakan rencana tindakan untuk melaksanakan tindakan perbaikan dan peningkatan kualitas produk yang dihasilkan setelah mengetahui penyebab kerusakan atas terjadinya jenis-jenis kerusakan produk, maka disusun suatu rekomendasi atau usulan tindakan perbaikan secara umum dalam upaya menekan tingkat kerusakan produk. 
Tabel 6. Usulan Tindakan Perbaikan

\begin{tabular}{|c|c|c|}
\hline Unsur & Faktor Penyebab & Usulan Tindakan Perbaikan \\
\hline Manusia & $\begin{array}{l}\text { 1. Kurang displin } \\
\text { dan malas bekerja } \\
\text { 2. Tidak teliti dalam } \\
\text { pengontrolan } \\
\text { proses produksi } \\
\text { 3. Kurang fokus dan } \\
\text { kelelahan }\end{array}$ & $\begin{array}{l}\text { 1. Karyawan yang terlibat langsung dalam proses } \\
\text { produksi harus fokus dan displin dalam bekerja. } \\
\text { 2. Perlu adanya tim pengawas agar ketika bekerja } \\
\text { dapat kontrol pekerjaannya sesuai dengan standar } \\
\text { yang telah ditentukan. } \\
\text { 3. Perlu adanya pelatihan (tranning) dalam } \\
\text { memotivasi semangat kerja dan memberikan bonus } \\
\text { bagi karyawan yang berprestasi sebagai bentuk } \\
\text { penghargaan (reward) }\end{array}$ \\
\hline Material & $\begin{array}{l}\text { 1. Gelasnya retak- } \\
\text { retak, sobek dan } \\
\text { tidak sesuai } \\
\text { ukuran. } \\
\text { 2. Bahan baku } \\
\text { plastik tidak } \\
\text { sesuai spesifikasi } \\
\text { 3. Tempat } \\
\text { Penampungan } \\
\text { Kurang Besar }\end{array}$ & $\begin{array}{l}\text { 1. Sebaiknya sebelum penggunaan bahan baku, } \\
\text { terlebih dahulu harus dilakukan pengecekan tentang } \\
\text { gelas plastik yang digunakan } \\
\text { 2. Harus bisa memastikan bahwa bahan baku plastic } \\
\text { yang dipesan sesuai dengan spesifikasi yang } \\
\text { ditentukan } \\
\text { 3. Perlu adanya tempat penampungan yang cukup } \\
\text { besar agar bisa menampung cukup banyak air yang } \\
\text { dibutuhkan }\end{array}$ \\
\hline Mesin & $\begin{array}{l}\text { 1. Motor penggerak } \\
\text { tidak beroperasi } \\
\text { dengan baik. } \\
\text { 2. Mesin tidak } \\
\text { Stabil } \\
\text { 3. Produk bocor } \\
\text { dan cetakan logo } \\
\text { miring }\end{array}$ & $\begin{array}{l}\text { 1. Pastikan mesin (machine) yang digunakan selama } \\
\text { proses produksi harus tetap stabil } \\
\text { 2. Dilakukan pengecekan secara berkala atau } \\
\text { pembersihan mesin ketika selesai proses produksi } \\
\text { serta melakukan perbaikan terhadap komponen } \\
\text { mesin yang terganggu } \\
\text { 3. Pastikan produk tidak mengalami kecacatan }\end{array}$ \\
\hline Metode & $\begin{array}{l}\text { 1. Overload } \\
\text { produksi } \\
\text { 2. Produksi secara } \\
\text { simultan } \\
\text { 3. Pengisian air } \\
\text { yang kurang } \\
\text { merata. }\end{array}$ & $\begin{array}{l}\text { 1. Produksi harus sesuai standar ukuran yang pasti dan } \\
\text { berpatokan pada komposisi bahan yang tersedia. } \\
\text { 2. Melakukan produksi secara parsial agar jumlah } \\
\text { produk yang dihasilkan sesuai dengan permintaan } \\
\text { konsumen berdasarkan standar operasional } \\
\text { prosedur yang ditetapkan oleh perusahaan. } \\
\text { 3. Pengisian air harus merata sesuai dengan ukuran } \\
\text { dan spesifikasi yang ditetapkan }\end{array}$ \\
\hline Lingkungan & $\begin{array}{l}\text { 1. Bencana alam } \\
\text { 2. Cuaca Kurang } \\
\text { Mendukung } \\
\text { 3. Air keruh } \\
\text { dipengaruhi } \\
\text { derasnya air } \\
\text { sungai. }\end{array}$ & $\begin{array}{l}\text { 1. Air yang keruh harus dilakukan penyaringan yang } \\
\text { ketat agar sesuai dengan kualitas air yang } \\
\text { diproduksi. } \\
\text { 2. Lingkungan harus kondusif agar para pekerja } \\
\text { merasakan kenyaman dalam bekerja dan } \\
\text { membentuk kebiasaan (culture) kerja yang saling } \\
\text { memotivasi sehingga dapat memberikan suasana } \\
\text { yang menyenangkan bagi para pekerja. }\end{array}$ \\
\hline
\end{tabular}




\section{Tahap Control}

Tahap control merupakan tahap analisis terakhir dari proses penerapan metode six sigma yang menekankan pada pendokumentasian dan penyebarluasan dari tindakan yang telah dilakukan meliputi:

a. Melakukan perawatan dan perbaikan mesin pabrik secara berkala serta berkelanjutan (sustainable).

b. Melakukan pengawasan terhadap bahan baku dan karyawan bagian produksi agar kualitas (mutu) barang yang dihasilkan lebih baik.

c. Melakukan pencatatan seluruh produk catat setiap hari dari masing-masing jenis dan mesin, yang dilakukan oleh karyawan dalam proses produksi.

d. Melaporkan hasil pencatatan produk rusak berdasarkan type produk catat kepada supervisor dan total produk rusak dalam periode satu bulan dicantumkan dalam montly manager.

\section{KESIMPULAN}

Berdasarkan hasil penelitian di atas maka dapat disimpulkan yaitu pertama, tahap define merupakan mendefinisikan masalah standar kualitas dalam proses produksi perusahaan, mendefinisikan rencana tindakan yang harus dilakukan serta menetapkan sasaran dan tujuan peningkatan kualitas Six Sigma. Kedua, tahap measure. Pada tahapan ini pengukuran karakteristik kualitas produk yang dihasilkan pada proses produksi dilakukan oleh perusahan sehingga peneliti hanya melakukan pengumpulan data atau dokumentasi yang telah dibuat oleh pihak bagian produksi. Ketiga, tahap analyze dihitung mulai dari nilai Central Limit, Upper Control Limit (UCL), Lower Control Limit (LCL) serta perhitungan DPMO dan nilai Sigma. Berdasarkan perhitungan nilai Sigma, rata-rata tingkat sigma 1,929 atau berada pada kondisi 2 sigma dengan kemungkinan kerusakan sebesar 335.287 untuk sejuta kali proses produksi atau sebesar 33,5\% Defect Per Million Opportunities (DPMO). Reject Pabrik dengan persentase dari total kerusakan adalah $57,1 \%$ dan Reject Supplier sebanyak 42,9\%.

Keempat, tahap improve yaitu dengan melakukan pelatihan bagi karyawan dan melakukan pengawasan pada karyawan bagian produksi, perawatan dan perbaikan mesin secara berkala dan pemilhan kualitas bahan baku yang akan digunakan dalam proses produksi serta pengelompokan produk cacat berdasarkan jenis kecacatan, melakukan pengamatan setiap minggu, pendataan cacat produksi dilakukan secara detail, pengontrolan produk cacat dilakukan dengan baik, skill dan kesadaran operator harus ditingkatkan, supervisor bertanggungjawab terhadap produk cacat masingmasing area. Kelima, tahap control yaitu dengan melakukan pencatatan dan penimbangan produk cacat dari masing-masing jenis kerusakan, melaporkan hasil penimbangan kepada supervisor dan pengawasan terhadap produksi oleh ketua bagian produksi secara terus menerus.

Kegiatan pengendalian kualitas tersebut, bisa dikatakan bahwa perusahaan cukup memberikan manfaat dalam upaya mengurangi kegagalan produk akan tetapi masih 
belum maksimal. Sehingga perlu disarankan yaitu sebaiknya perusahaan meningkatkan kapabilitas Sigma, meningkatkan proses dengan cara melakukan perbaikan terhadap mesin, bahan baku, metode dan lingkungan serta pembinaan dan pengawasan kerja karyawan.

\section{DAFTAR PUSTAKA}

Fursule, Nilesh V., at all. 2012. Understanding the Benefits and Limitations of Six Sigma Methodologi. International Journal of Scientific and Research Publication. Vol 2. Issue 1. ISSN 2250-3153

Ganguly, Kunal. 2012. Improvement Process For Rolling Mill Through The Dmaic Six Sigma Approach. International Journal for Quality research. Vol 6, No. 3.

Gaspersz, Vincent. 2005. Pedoman Implementasi Program Six Sigma Terintegrasi dengan ISO 9001:2000, MBNQA, dan HACCP. Jakarta: Gramedia Pustaka Utama.

Haryono, D. 2017. Pengendalian kualitas produksi dengan model grafik kontrol p pada PT. Asera Tirta Posidonia. Jurnal Varian, 1(1), 27-34.

Hung, siang-Chin and Ming-Hsien Sung. 2011. Applying six sigma to manufacturing processes in the food industry to reduce quality cost. Scientific Research and Essays Vol. 6(3): 580-591.

Irwan, I., dan Haryono, D. 2015. Pengendalian Kualitas Statistik (Pendekatan Teoritis dan Aplikatif). Bandung: Alfabeta.

Kabir, Md. E., at, all. 2013. Productivity Improvement by using Six-Sigma. International Journal of Engineering and Technology. Volume 3 No. 12.

Latief, Y. dan R. P. Utami. 2009. Penerapan Pendekatan Metode Six Sigma Dalam Penjagaan Kualitas Pada Proyek Konstruksi. Jurnal Makara Teknologi. Volume 13 No.2.

Montgomery, D. C. 2008. Introduction to Statistical Quality Control. New York: John Wiley \& Sons Inc.

Pande, Pate and Larry Holpp. 2002. What is Six Sigma?. New York: McGraw-Hill

Taneja, Mohit and Arpan Manchanda. 2013. Six Sigma an Approach to Improve Productivity in Manufacturing Industry. International Journal of Engineering Trends and Technology (IJETT) - Volume 5 Number 6.

Thakore, R. 2014. A Review: Six Sigma Implementation Practice in Manufacturing Industries. nt. Journal of Engineering Research and Applications. Vol. 4, Issue 11(Version - 4). 